\title{
CARTOGRAFIA DE UMA EXPERIÊNCIA DE ESTÁGIO DE UM ESTUDANTE DE PSICOLOGIA EM UMA ESCOLA: RELATO DE EXERIÊNCIA ${ }^{1}$
}

\author{
CARTOGRAPHY OF A STAGE EXPERIENCE OF A PSYCHOLOGY STUDENT \\ AT A SCHOOL: EXERIENCE REPORT
}

\author{
Ederson Juliano Sezimbra ${ }^{2}$ e Douglas Casarotto de Oliveira ${ }^{3}$
}

\section{RESUMO}

Neste relato de experiência, é apresentada uma cartografia de uma experiência de estágio de um estudante de psicologia em uma escola do interior do Rio grande do Sul durante o ano de 2015. O qual tem como objetivo geral problematizar a respeito das práticas da Psicologia na escola e como objetivos específicos, demonstrar as práticas da educação de Jovens e Adultos (EJA) bem como analisar o papel da Psicologia ao proporcionar local de diálogo e discussões aos estudantes no âmbito escolar. A metodologia foi construída na perspectiva cartográfica, com uso dos diários de campo e dos conceitos de análise de implicação e analisador propostos por Baremblit (2002) e do conceito de Desejo em três movimentos (ROLNIK, 2014). Os resultados demonstraram que a presença do estagiário causava no início certa desconfiança porém ao se colocar à disposição da equipe de psicologia da escola e começar a atuar junto ao PIBID foi criada uma relação de confiança e as demandas existentes começaram a surgir e reconhecer no saber trazido pelo estudante um lugar de escuta e acolhimento, o qual pode contribuir através de dispositivos e do uso do conceito intercessores, em múltiplos aspectos da escola retirando o pensamento dos indivíduos de sua imobilidade. A conclusão demostra que o território tão buscado pelo estagiário na escola não se revelou como este desejava ou imaginava que devesse acontecer, foi preciso criar um outro modo de coexistir no espaço escolar onde a liberdade de transitar em diversos lugares seria a sua prática fundamental.

Palavras-chave: Estágio específico, Psicologia escolar, Análise Institucional.

\section{ABSTRACT}

This experience report presents a cartography of an internship experience of a psychology student at a school in the interior of Rio Grande do Sul during the year 2015. The general objective of which is to discuss the practices of Psychology at school and as specific objectives, demonstrate the practices of Youth and Adult education (EJA) as well as analyze the role of Psychology in providing a place for dialogue and discussions to students in the school environment. The methodology was built in the cartographic perspective where the field diaries and the concepts of implication analysis and analyzer proposed by Baremblit (2002) and the concept of Desire in three movements (ROLNIK, 2014) were used. The results showed that the presence of the trainee initially caused some distrust, however, by placing himself at the disposal of the school's psychology team and starting to work with PIBID, a relationship of trust was created and the existing demands began to emerge

\footnotetext{
1 Relatório de estágio específico.

2 Psicólogo graduado pela Faculdade Integrada de Santa Maria - FISMA - Santa Maria/RS (2010-2015) - CRP 07/25.851. Coordenador de grupos pelo Instituto Pichon Rivière, Pós-graduando em educação pela Faculdade Faveni. E-mail: sezimbra.psicologia@gmail.com.

3 Psicólogo, graduado pela Universidade Federal de Santa Maria, (2004) CRP 07/12885. Mestre em Educação - UFSM, Esp. em Violência Doméstica Contra Crianças e Adolescentes- USP, Esp. Em Humanização da Atenção da Gestão do SUS- UFRGS, Professor de Psicologia na Faculdade Integrada de Santa Maria - FISMA - Santa Maria/ RS. Doutorando pela Universidade Federal do Rio Grande do Sul - UFRGS. E-mail: douglascasarotto@gmail.com
} 
and recognize the knowledge brought by the student a place of listening and welcoming, which can contribute through devices and the use of the intercessor concept, in multiple aspects of the school, removing the thought of individuals from their immobility. The conclusion shows that the territory so sought after by the trainee at school did not turn out as he wanted or imagined it should happen, it was necessary to create another way of coexisting in the school space where the freedom to move in different places would be his fundamental practice.

Keywords: Specific internship, School Psychology, Institutional Analysis.

\section{INTRODUÇÃO}

Este artigo apresenta uma Cartografia de uma experiência de estágio de Psicologia em uma escola numa cidade no interior do Rio Grande do Sul ocorrida durante o ano de 2015. Nessa escola são atendidos alunos do ensino médio nos turnos manhã e tarde e no turno noite os alunos da EJA. Durante os estágios foi possível vivenciar momentos diversos e divergentes como por exemplo a greve que ocorreu naquele ano, ocorreram também momentos em que houve a possibilidade de criar ambiente de diálogo com os estudantes e trabalhadores da escola. Especialmente nos encontros com os alunos da Educação de Jovens e Adultos (EJA), nas aulas de ética e de filosofia e em outras oportunidades onde houve demanda apresentada por professores, alunos e o serviço de Psicologia na escola.

A EJA, segundo Sampaio (2009) se constitui de uma trama entre Estado, fatores econômicos, ideológicos, políticos e sociais entre outras esferas sociais, formando parcerias para oferecer projetos educacionais, em geral não há uma política estruturada e sistematizada a população alvo desse direito (SAMPAIO, 2009).

Dessa maneira conforme Passos, Kastrup e Escócia (2009) foi sendo desenhada a cartografia na escola, passo a passo, onde não havia um percurso ou método prescrito para intervir. O que se desejava era permitir durante o trabalho a criação de linhas de fuga do desejo, saídas para as intensidades que pedissem passagem (ROLNIK, 2014).

Destarte esse artigo tem por objetivo geral problematizar a respeito das práticas da Psicologia na escola. E como objetivos específicos, demonstrar as práticas da educação de Jovens e Adultos (EJA) e analisar o papel da Psicologia ao proporcionar local de diálogo e discussões aos estudantes no âmbito escolar.

\section{MÉTODO}

Este artigo foi construído na perspectiva de uma cartografia, a qual acontece ao mesmo tempo em que se faz, e seus desenhos seguem os movimentos de transformação das paisagens (ROLNIK, 2014). Dessa forma, para tornar possível cartografar a experiência de estágio, foram utilizados como materialidade os diários de campo, em que foram relatadas as práticas e as impressões deixadas durante a experiência. 
O conceito de análise de implicação foi o recurso que proporcionou descrever o que a entrada nos estágios e seu desenrolar causaram, de acordo com Baremblitt (2002) esse é um processo que acontece quando os profissionais entram em contato com a organização que se propõe analisar. Esse fenômeno tem origem inconsciente, mas também está permeado de múltiplas materialidades, devendo ser analisado em todas as dimensões, pois acontece de forma dinâmica e recíproca entre a organização analisada e o analista institucional.

Para possibilitar a análise de momentos vivenciados no estágio, foram eleitos analisadores. Baremblitt (2002) diz que um analisador não privilegia apenas os acontecimentos verbais, qualquer materialidade pode ser seu suporte, sua forma de expressão é totalmente heterogênea. O Analisador não possui como função apenas exprimir algo, ele mesmo contém elementos para se auto entender e autoanalisar, dessa forma esse trabalho se baseia também na autoanálise do estudante em formação.

Nesse percurso se fez uso do conceito-ferramenta intercessores (VASCONCELOS, 2007), eles estarão presentes quando nos referirmos as práticas da Psicologia que proporcionaram na instituição, momentos em que foi possível movimentar pensamentos e conceitos, criá-los como forma de pensar novos modos de existência na escola, aos profissionais, aos alunos e a todos os seus agentes.

\section{DISCUSSÃO E RESULTADOS}

A greve num contexto histórico, segundo Silva (2014) era classificada como delito, devido aos prejuízos que causa. Atualmente, passou a ser reconhecida como fato socialmente útil, reconhecido como direito a ser garantido pela justiça. Essa atuação coletiva, de paralisação das atividades, é a forma de exteriorizar a insatisfação com o trabalho, como forma de forçar a negociação e o atendimento de reivindicações.

Podemos vivenciar essa realidade trazida pela greve durante o início do segundo semestre na escola. Nos primeiros dias, observamos as reuniões que eram feitas entre os professores para decidirem sobre as paralisações, essas ocorreram em dias estabelecidos com tempo determinado durante algumas semanas. No decorrer das próximas semanas acabou culminando com a decisão pela greve com tempo determinado, mais adiante em novas reuniões houve a decisão pela greve com tempo indeterminado.

Esse clima causa grande mal-estar nos profissionais, as votações aconteciam em horários de aula, os alunos ficavam à espera dos resultados, isso causava ansiedade nos professores, pois os alunos vinham pra escola, e em seguida eram dispensados, situação que temiam trazer desconforto na relação professores, pais e alunos.

Timm (2010) disserta sobre o mal estar na docência, conforme o autor quando ao se referir a esse tema se tem pelo menos duas possibilidades, a primeira delas evidencia-se no acomodar-se, e passar a fazer parte do grupo que apenas lamenta sua condição a espera que as coisas mudem. Em contra partida a outra possibilidade apresenta comportamento onde há compromisso 
estabelecido consigo mesmo na busca de melhor trabalhar sua autoestima durante o processo de subjetivação docente.

Durante as reuniões dos professores uma característica era recorrente, o afeto envolvido, pois se percebe uma diminuição da potência dos envolvidos, podendo-se associar esse comportamento com as ideias apresentadas por Deleuze (2002) que diz que um mau encontro, surge da oposição de um corpo exterior em contato com outro corpo. No caso da escola esse encontro acontece entre professores e Estado, numa relação de forças que não se compõe.

\section{INÍCIO DAS PRÁTICAS DE ESTÁGIO NA ESCOLA}

A proposta de estágio na escola foi, desde o início, desafiadora em diversos aspectos. O mais evidente ficou a cargo do modo em que essa prática se evidenciou, havia o desejo de estagiar em áreas da saúde, no entanto devido a diversos motivos não foi possível. Houve então a sugestão da coordenação do curso para estagiar no colégio, o que inicialmente gerou surpresa, a principal questão que se apresentava era se havia a possibilidade de se pensar práticas relacionadas à saúde numa escola.

Iniciamos o estágio com um sentimento de incerteza quanto às práticas que seriam desempenhadas, mal-estar que acabou por acompanhar muitos momentos de estágio. Passamos a ter a necessidade de compreender sobre o que fazia surgir esses sentimentos sobre o que acontecia. Foi através do conceito Desejo em Três Movimentos (ROLNIK, 2014) que esse entendimento foi encontrado, movimentos do desejo que serão melhor descritos durante esse relato.

A entrada na escola, e a apresentação a equipe de psicologia atuante no local, e em seguida aos demais agentes, pode ser entendida como propõe Rolnik (2014) na perspectiva do Movimento Um do desejo. Esse é o momento de simulação, pois durante esse processo não é possível reconhecer um lugar e nem saber ao certo quem são as pessoas ao qual se entra em relação. Os encontros operam em movimentos de atração e de repulsa, as subjetividades atuam como máscaras enquanto procuram um lugar, buscando formas de expressão (ROLNIK, 2014).

Passadas as simulações são desenhadas outras formas. As práticas lentamente começam a acontecer, as atividades tinham como proposta inicial atuar na EJA, mas havia a necessidade de cumprimento de extensa carga horária, observou-se que o turno manhã também apresentava demandas. Sendo assim decidiu-se atuar nos dois turnos, nesse movimento pode-se pensar em perspectivas diferentes: a primeira representada pela EJA; à segunda relacionada à atuação no turno manhã. As visitas começaram a acontecer durante o dia, inicialmente era possível sentir que a presença de um novo elemento representado pelo estudante causava desconfiança e mal-estar nas profissionais.

Então foi necessário criar estratégias para burlar essa sensação dessa forma se decidiu que seria preciso se aproximar do psicólogo que atuava na escola. Observou-se que suas práticas eram bastante requisitadas junto ao colégio sendo assim pôs-se a disposição para possíveis trabalhos. A partir de 
então se passou a fazer acolhimentos aos alunos, prática essa que às vezes acontecia em conjunto com os colegas estagiários de observação, esse movimento propiciou criar uma relação de confiança como propõe Adaime (2007).

Pois ao estabelecer essa relação com o Serviço de apoio educacional (SOE) que atua como suporte na assessoria a equipe diretiva da escola e da coordenação pedagógica, o mesmo passou a nos dias seguintes do estágio a imediatamente encaminhar alunos que precisavam de uma escuta ou acolhimento.

Foi também pela manhã que houve o contato com o PIBID/Hstória que é um Programa Institucional de Bolsas de iniciação à Docência o qual possibilitou o primeiro convite para participar de um encontro com uma turma do segundo ano para discutir sobre um filme que a turma havia assistido dias antes.

Ao se apresentar, esse processo que passou a acontecer durante os estágios na escola depara-se com o Movimento Dois do desejo (ROLNIK, 2014). Nesse ponto, os territórios passam a se constituir. Dessa forma, começamos o reconhecimento de um lugar de atuação no colégio. As práticas de estágio ganhavam assim características de atuação de psicologia, o mal-estar inicial dava espaço ao sentimento de fazer parte. No entanto, devemos ter cautela, a sensação de se sentir em casa ocasionada pelo Movimento Dois pode fazer com que as ideias se cristalizem e permitir isso é barrar fluxos do desejo.

Passado esse momento de certa euforia, abriu-se lugar para o Movimento Três (ROLNIK, 2014). Nele os territórios já se encontram formados, surge a vontade de manter o bem estar causado pela formação desse território. No entanto, quando se deseja permitir linhas de fuga do desejo não se deve conceber a ideia de que se precisa ficar por muito tempo ocupando o mesmo espaço. Os territórios então por ora formados devem se movimentar a fim de possibilitar a vida, é necessário criar outros modos de existência.

Na perspectiva da análise institucional se pode conceber que esses movimentos se relacionam com o conceito da análise de implicação proposta por Baremblitt (2002). O mal-estar vivenciado na escola era ocasionado pelas impressões causadas no analista, frente ao campo de trabalho que se apresentava. O autor define esse processo como fenômeno bastante complexo, que não se apresenta apenas de forma reativa, mas, sobretudo é um processo recíproco e simultâneo entre o analista, nesse caso representado pelo estagiário e a instituição analisada, o colégio em questão.

\section{Projeto Psicologia/PIBID}

O encontro com o PIBID/História aconteceu logo no início do estágio, como já relatado foi através de convite da professora coordenadora que houve o primeiro contato com os alunos em sala de aula. Esse processo foi se desenvolvendo durante todo o primeiro semestre em encontros furtivos, o que se desejava era proporcionar discussões sobre temas diversos com os alunos da EJA. Essas atividades passaram a tomar proporções de projeto a partir do segundo semestre deste mesmo ano. 
A proposta que passava a ser aplicada não era mais de ser apenas um colaborador da disciplina, mas alguém que pudesse elaborar as regências (aulas) junto à professora responsável e suas estagiárias. Foi então que se passou a ter um lugar fixo no colégio durante os dias dessa disciplina, onde se tinha encontros com os alunos das turmas, atividade que preenchiam todos os períodos da noite.

As materialidades utilizadas eram variadas geralmente ligadas à arte como, filmes, textos literários, músicas. Eram criados lugares de problematizações e discussões, através de análises dos temas presentes no cotidiano dos alunos. As atividades não ficavam restritas apenas a fala, pois os alunos de acordo com a proposta do dia podiam se expressar através de desenhos, pinturas, colagens, escritos.

Desse modo o que se desejava era permitir o pensar, para arejar pensamentos estratificados. Nesse ponto, passaram a surgir os primeiros intercessores como descritos por Passos e Barros (2000), ao mesmo tempo, quem criava os intercessores e também um deles. Aos intercessores o que interessa é o movimento, aproximando-se daquilo que acontece no "entre" no encontro, no caso do estágio os encontros com os alunos davam a possibilidade de colocar em prática lugares em que era possível criar novos modos de existência, através da experimentação (PASSOS; BARROS, 2000).

Esses agenciamentos iam ao encontro do que refere Baremblitt (2002) quando trata do conceito de dispositivo. Conforme o autor esses funcionam ao mesmo tempo em que se formam, sua formação está sempre a serviço do desejo e da vida. Durante as suas montagens os dispositivos geram acontecimentos transformadores, tem por objetivo conectar singularidades produzindo linhas de fuga do desejo, o dispositivo tem a capacidade de incluir sujeitos e com isso tornar possível que se concretizem suas realizações.

\section{Orientação Profissional}

O trabalho feito pelo profissional de psicologia responsável na escola ocupa território importante na instituição, suas práticas são diversas, podendo ser uma fala aos alunos em sala de aula sobre temas que lhes interessem, intervenções, acolhimentos. Foi a partir desse último que tivemos os primeiros contatos com os alunos da manhã. Nos acolhimentos, os jovens aproveitavam para falar de momentos de crise vivenciados por eles. Por ser público heterogêneo os assuntos eram singulares, no entanto havia a orientação de sempre deixar claro que não se tratava de trabalho clínico e, caso percebêssemos demanda para atendimento, era recomendável o encaminhamento a outro profissional.

Martinez (2010) refere que a atuação do psicólogo na escola está relacionada a uma representação social que direciona como esse profissional deve trabalhar. Dessa maneira, sua atuação está voltada ao modelo clínico clássico de atendimento e diagnóstico de crianças com dificuldades emocionais e de comportamento. As formas de atuação do psicólogo escolar são múltiplas, como a avaliação, diagnóstico, encaminhamentos, orientação a alunos e pais, formação e orientação de professores, orientação profissional. 
A orientação profissional, segundo Noronha e Ambiel (2006) auxilia o indivíduo a se conhecer, possibilitando uma escolha profissional mais lúcida, madura e ajustada às habilidades de cada um e, desse modo, ser promotora de saúde para os alunos. Martinez (2010) salienta que essa tem sido a forma específica de orientação ao trabalho que psicólogos vem desenvolvendo no ensino médio. Através de testes, caracteriza habilidades e interesses dos alunos promovendo espaço de autoconhecimento, reflexão e elaboração de planos e projetos profissionais.

A demanda por aplicar esse dispositivo foi criada por uma professora que tinha interesse em orientar seus alunos nesses aspectos. Dessa forma sugeriu ao psicólogo da escola esse trabalho com os terceiros anos. No mesmo dia o psicólogo da escola fez o convite para que atuasse nesse projeto, confiando a este a aplicação da orientação profissional. O mesmo possuía todo o material e encaminhou para que se inteirasse da atividade. Dessa forma começaram as aplicações nos alunos, essas consistiam em sete encontros onde seriam abordados temas relacionados a escolhas, família e trabalho culminando ao final com a aplicação de um teste psicológico.

Nessa prática, ficamos diante de um espaço mais assimétrico ocupado pelo psicólogo na escola, pois eram aplicados aos alunos diversos questionários com o propósito de conhecê-los. Buscava-se, assim, no início das atividades ou nos intervalos entre uma pergunta e outra, criar lugar de fala e reflexão para suavizar a característica pautada na avaliação. Alguns aproveitavam esses momentos para falar de suas angústias e dúvidas, mas em geral eram poucos minutos empregados nesse momento, pois os jovens pareciam mais preocupados com as perguntas e respostas ou simplesmente porque não se sentiam à vontade ou não queriam falar.

Essa atividade ocupou boa parte do estágio, e um dos fatores mais marcantes foi a possibilidade de ter a dimensão das diferentes formas de atuar na escola. Ao aplicar, a orientação profissional ocupava um lugar do que se imagina socialmente que deva desempenhar um psicólogo, com certo distanciamento dos alunos, pois era um aplicador de teste, um avaliador, ao contrário do que aconteceu durante a mesma aplicação com alunos da EJA e outras atividades desenvolvidas onde se estava mais próximo dos estudantes. Essas atividades possibilitaram perceber que a psicologia pode desempenhar múltiplos papéis no âmbito institucional e que suas práticas vão estar associadas aos modos de trabalho desses profissionais.

\section{CONSIDERAÇÕES FINAIS}

Nos dias em que não haviam atividades fixas com as turmas, costumávamos andar pelos corredores, nesse momento era possível ver o saber acontecendo, através das regências e observar a potência dos professores em suas práticas e a energia por eles depositada no ensino, mesmo em turmas com público reduzido. Os alunos traziam também sua potência a esses espaços, pois estavam na escola em busca de conhecimento e através deles acreditavam em mudanças em suas vidas. 
O mal-estar sentido durante a atuação na escola esteve de algum modo sempre presente, pois havia o desejo de ocupar um lugar, mas que lugar era esse? Provavelmente se fizermos uma autoanalise como sugere Baremblitt (2002) esse lugar não existia, já que assim como atuam os intercessores na perspectiva apresentada por Vasconcelos (2005) é necessário criar conceitos a todo o momento e para isso se devem arejar estratificações do pensamento, movimentá-lo.

Concluímos este relato de experiência com a compreensão de que as atividades desempenhadas no colégio, até certa medida, buscavam uma coexistência: existir entre profissionais docentes que tinham sua prática e atuação consagradas e determinada por critérios éticos e técnicos da profissão. Nossa prática não teve, em primeira instância, a sala de aula como território, sendo assim estar na escola era poder transitar em certa liberdade por múltiplos espaços, movimento possibilitado através da criação dos dispositivos, devires que possibilitavam a transformação em professor, ouvinte, articulador, regente, aluno. Nessa experimentação diária, podemos pensar que talvez essa seja a forma de atuação dos psicólogos na escola e em qualquer lugar, onde não se deve tentar a todo custo encontrar um lugar, mas sim habitar todos os territórios e vivências que se apresentarem possíveis.

\section{REFERÊNCIAS}

ADAIME, R. D. Clínica Experimental: Programa para Máquinas Desejantes. São Paulo, 2007. Dissertação (Mestrado em Psicologia) - Núcleo de Estudos da Subjetividade, Pontifícia Universidade Católica de São Paulo.

BAREMBLITT, G. Compêndio de Análise Institucional e outras Correntes: Teoria e Prática. 5. ed. Belo Horizonte: Instituto Félix Guattari, 2002.

DELEUZE, G. Espinosa: Filosofia Prática. São Paulo: Escuta, 2002.

MARTINEZ, A.M. O que pode fazer o psicólogo na escola? Em Aberto, Brasília, v. 23, n. 83, p. 39-56, mar. 2010.

NORONHA, A.P.P; AMBIEL, R.A.M. Orientação profissional e vocacional: análise da produção científica. Psico-USF, v. 11, n. 1, p. 75-84, jan./jun. 2006.

PASSOS, E; BARROS, R. B. de. A Construção do Plano da Clínica e o Conceito de Transdisciplinaridade. Psic.: Teor. e Pesq., Brasília, Jan-Abr 2000, v. 16, n.1, p. 71-79. 
PASSOS, E.; KASTRUP, V. e ESCÓSSIA, L. da. (org.). Pistas do método da cartografia: Pesquisa-intervenção e produção de subjetividade. Porto Alegre: Sulina, 2009.

ROLNIK, Suely. Cartografia Sentimental: Transformações Contemporâneas do Desejo. 2. ed. Porto Alegre: Sulina; Editora da UFRGS, 2014.

SAMPAIO, Marisa Narcizo. Educação de Jovens e Adultos: Uma História de Complexidade e Tensões. Práxis Educacional, Vitória da Conquista, v. 5, n. 7 p. 13-27 jul./dez. 2009.

SILVA, Otavio Pinto e. Greve e ética na Universidade. Estudos Avançados, v. 28, n. 80, 2014.

TIMM, E.Z. O mal-estar na docência em tempos líquidos de modernidade. Revista Mal-estar e Subjetividade, Fortaleza, v. 10, n. 3, p. 865-885, set/2010.

VASCONCELLOS, J. A Filosofia e seus Intercessores: Deleuze e a Não-Filosofia. Educ. Soc., Campinas, v.26, n. 13, p. 1217-1227, Set./Dez. 2005. 